\title{
GENERATION TIME RATIO, RATHER THAN VORACITY, DETERMINES POPULATION DYNAMICS OF INSECT - NATURAL ENEMY SYSTEMS, CONTRARY TO CLASSICAL LOTKA-VOLTERRA MODELS
}

\author{
PAVEL KINDLMANN ${ }^{1,2, *}$, ZUZANA ŠTÍPKOVÁ ${ }^{1,2}$, \\ and ANTHONY F. G. DIXON ${ }^{1,3}$ \\ ${ }^{1}$ Global Change Research Institute CAS, Bělidla 986/4a, 60300 Brno, Czech Republic \\ ${ }^{2}$ Institute for Environmental Studies, Faculty of Science, Charles University, Benátská 2, 12801 Praha 2, Czech Republic \\ ${ }^{3}$ School of Biological Sciences, University of East Anglia, Norwich, NR4 7TJ, UK \\ * Corresponding author: pavel.kindlmann@centrum.cz
}

\section{ABSTRACT}

Population dynamics of a predator-prey system is usually simulated by the classical Lotka-Volterra models, which were successfully applied to the population dynamics of snowshoe hare and lynx and many other predator-prey systems. Attempts were made to apply them also to insect predator-prey systems, but in terms of biological control, they did not reveal the features of the predators that control the abundance of their prey. The most conspicuous example of failure of Lotka-Volterra models applied to insect predator-prey systems are ladybird-aphid systems, in which these models usually fail to fit empirical data. Because of their practical importance and because they are very well studied, we have chosen aphid-ladybird systems as a model. We summarize the results published on various aspects of the population dynamics of aphid-ladybird systems and present them in the context of empirical data. Using new data, we more closely specify the existing metapopulation model of aphid-ladybird interactions.

Based on the arguments presented here, we conclude that the ladybird-aphid case can be generalized to insect (and maybe even other) predator-prey systems, where the ratio of the generation times of the predator to that of the prey (GTR) is large. In such systems, the main selection pressure on predators is choosing the best strategy to maximize survival of their offspring, rather than on maximization of the amount of prey eaten. Thus voracity, which is the main determinant of population dynamics in Lotka-Volterra models, loses its role and is replaced by optimization of the choice of oviposition sites in systems with large GTRs.

Keywords: aphids; ladybirds; Lotka-Volterra; metapopulation dynamics; predator-prey systems

\section{Introduction}

Population dynamics of a predator-prey system is usually simulated by the classical Lotka-Volterra models (Lotka 1920, 1925; Volterra 1926, 1931). These models were successfully applied to the population dynamics of snowshoe hare and lynx (e.g., Hoppenstead 2006; Carpenter 2018) and many other predator-prey systems. Attempts were made to apply them also to insect predator-prey systems (e.g., Varley et al. 1974; Hassell 1978), but in terms of biological control they did not reveal the features of the predators that control the abundance of their prey. The most conspicuous example of failure of Lotka-Volterra models applied to insect predator-prey systems are ladybird-aphid systems, in which these models usually fail to fit empirical data (Kindlmann et al. 2015). Understanding these systems, however, is very important in terms of classical biological control, as is outlined below.

The efficiency of ladybirds in aphid-ladybird systems is an important issue for biological control. Therefore, it has been the subject of many discussions and empirical studies, which attempt to evaluate the extent to which insect predators are able to suppress their aphid prey. The magnitude of the effect of predators on their prey is now questioned and evidence is increasing that pest regulation by predators is not as strong in nature (in contrast to confined habitats like glasshouses) as people would like to believe. Literature dealing with these complex problems, which touch on many different aspects, is scattered and a comprehensive compendium, enabling a multifactorial view of the situation, is missing.

Because of their practical importance and because they were very well studied, we have chosen the aphid-ladybird system as a model system. We summarize the results published on various aspects of the population dynamics of aphid-ladybird systems and present them in the context of empirical data. Using new data, we show that the existing metapopulation model of aphid-ladybird interactions (Kindlmann and Dixon 2003; Houdková and Kindlmann 2006) that describes the within-season dynamics within one patch can work, if only the ladybird dynamics on trees and large stands of vascular plants is considered. Small solitary vascular plants probably do not have a significant effect on ladybird dynamics.

Then we present one of the few examples of other metapopulation models of insect predator-prey dynamics (the only one to our knowledge) and conclude with a generalization of the ladybird-aphid case to most insect predator-prey systems.

\section{Ladybird-Aphid System as an Example of an Insect Predator-Prey System}

\section{Aphid dynamics}

Aphid populations usually grow exponentially in the initial phase of their development and on reaching a certain population density, the aphids switch to alate pro- 
duction and/or move to another part of the plant. The switch to migration can be seen as a response to deterioration in the quality of the host plant or severe intraspecific competition. The switch results in a rapid decline in colony size (Kindlmann and Dixon 1993). The adaptive significance of the response of aphids to their own density and deterioration in food quality, both of which result in migration, is discussed in Kindlmann and Dixon (1999a, 1999b, 2001, 2003).

\section{Optimal strategy of an aphid predator}

From an evolutionary perspective, both predator and prey strive to maximize their reproductive potentials. However, whilst the existence of prey is not dependent on predators, the latter are dependent on prey. Therefore, it is advantageous for predators to conserve their prey. Thus, for predators, the optimal strategy involves counteracting pressures to maximize their own reproduction and survival while conserving enough prey to sustain a sufficient food supply for their offspring. This is very nicely exemplified by long-lived insect predators, such as ladybirds, feeding on short-lived prey, such as aphids (Dixon and Kindlmann 1998; Kindlmann and Dixon 1999a, 1999b, 2001; Dostálková et al. 2002; Dixon et al. 2015). As most of these predators suffer enormous egg and larval mortality due to cannibalism (Dixon and Kindlmann 2012) and intraguild predation (Mills 1982), selection acts mainly on optimizing their oviposition strategies in terms of maximizing the likelihood that their offspring will survive until reproductive age. The oviposition strategy of a predator with a long larval developmental time will depend on a longer projection of the future prey abundance in a patch, bearing in mind there are likely to be more bottlenecks or a higher probability of a bottleneck than for predators with short developmental times. Consequently, the former must be more conservative in terms of conserving their prey (the GTR hypothesis, Dixon and Kindlmann 1998; Kindlmann and Dixon 1999a, 2001; Kindlmann et al. 2015). This hypothesis is now beginning to be more widely accepted (e.g., Mills 2018).

\section{Effectiveness of aphid predators in regulating the abundance of their prey}

Until recently, there was only one attempt to account for the low effectiveness of aphidophagous insect predators: Kindlmann and Dixon (1999a, 2001) propose that the ratio of the generation time of an insect predator to that of its prey (generation time ratio, GTR) determines their effectiveness in suppressing prey. Kindlmann and Dixon (1999a) assume that on a large spatial scale, at any instant, herbivore populations exist as patches of prey, associated with patches of good host plant quality. Predators exploit these patches, which vary greatly in number of prey both spatially and temporally (Kareiva 1990). GTR in insect predator-prey systems is often large: the developmental times of insect predators often span sev- eral prey generations and are similar to the duration of a patch of prey (Dixon 2000).

Cannibalism is common in insect predators (Fox 1975; Agarwala and Dixon 1993; Kindlmann and Dixon 1999a; Dixon and Kindlmann 2012) and is adaptive, as eating conspecific competitors will increase their fitness (Dong and Polis 1992). Mortality during larval stages can reach 99\% (Matsura 1976; Kirby and Ehler 1977; Wright and Laing 1982; Osawa 1993; Hironori and Katsuhiro 1997; Kindlmann et al. 2000). Because of the enormous larval mortality, the life history strategy of these predators is likely to be selected to maximize the probability of survival of their offspring, rather than maximize the number of eggs laid (Dixon et al. 1995, 1997; Kindlmann and Dixon 1999a).

In the majority of cases, the adult predators are winged and can easily move between patches, whereas the immature stages are confined to one patch throughout their development, and their survival is associated with the quality of the patch of prey in which they were born (Kindlmann and Dixon 1999a). Therefore, the fitness of most predators (such as aphidophagous ladybirds and hoverflies that feed on highly aggregated and ephemeral patches of prey, which is measured in terms of the number of offspring that survive to reproductive age), is likely to be more closely associated with their oviposition strategy (the choice of patch for laying eggs), than the trophic interactions commonly used in models of prey-predator population dynamics (Kindlmann and Dixon 1999a).

When GTR is large and cannibalism is common, eggs laid by predators late on in the existence of a patch of prey are highly likely to be eaten by larvae of predators that hatch from the first eggs to be laid (Kindlmann and Dixon 1999a). In addition, because of the large GTR, there is insufficient time for the larvae that hatch from late laid eggs to complete their development. Thus, cannibalism and the ephemeral existence of patches of prey pose constraints such that females that can assess the age of a patch of prey gain an advantage (Kindlmann and Dixon 1999a).

As a consequence, females oviposit in young patches ("egg window hypothesis", Dixon 2000). The short "egg window" during which it is advantageous to lay eggs in a patch of prey in large-GTR systems reduces the number of eggs laid per patch. Incidence of cannibalism is likely to be proportional to the probability of encountering another predator, rather than prey, i.e., to the relative abundance of predators to prey ("meet and eat hypothesis", Kindlmann and Dixon 2003). If this is true, then even if predators are abundant and many eggs are laid in a patch of prey during the egg window, strong density dependent cannibalism greatly reduces the abundance of the predators (Mills 1982).

There is a simple mechanism, which enables predatory females to oviposit only in young colonies. Ovipositing females strongly react to the tracks of coccinellid larvae, which indicate that predatory larvae are present 
and might cannibalize their eggs. Thus, the presence of larval tracks is a good cue that it is time for the predatory females to leave a patch (Doumbia et al. 1998).

\section{Empirical verification of predator efficiency}

The efficiency of predators in suppressing their prey is assessed mainly by indirect methods such as by using cages to exclude predators (Chambers et al. 1983; Elliott and Kieckhefer 2000; Michels et al. 2001; Basky 2003; Cardinale et al. 2003; Schmidt et al. 2003; Costamagna and Landis 2006, 2007). However, cages change the microenvironment (Hand and Keaster 1967), especially temperature, which is thought to be important in determining the outcome of predator-prey interactions (Frazer and Gilbert 1976; Frazer et al. 1981). Also, cages with a large $(8 \mathrm{~mm})$ mesh size, especially those used by Schmidt et al. (2003) do not prevent predators from entering cages (Ameixa and Kindlmann 2011). The most serious problem with exclusion cages is that they do not allow the aphids to leave a cage, which obscures the results, as it is not possible to distinguish, whether the larger number of aphids inside cages compared to their numbers outside cages, is caused by predators eating the aphids outside cages, or to the aphids being prevented from leaving the cage. For all these reasons, exclusion cages cannot be used for measuring the effect of predators on aphid numbers.

Also the positive correlations often reported between aphid and predator abundances (Rutledge et al. 2004; Nielsen and Hajek 2005; Rutledge and O'Neil 2005; Desneux and Joo 2006) do not indicate anything about predator efficiency, as they may only indicate that predators concentrate where aphids are abundant rather than predators determine the abundance of aphids.

Thus, other methods must be used for assessing predator efficiency in aphid - natural enemy systems. One such method is the daily manual removal of all stages of predators from some plants but not control plants and then the comparison of the numbers of aphids on both groups of plants, as in Kindlmann et al. (2015). In a three-trophic system consisting of Hibiscus syriacus shrubs, aphid Aphis gossypii and ladybirds Coccinella septempunctata and Harmonia axyridis, Kindlmann et al. (2015) have shown that daily hand-removal of all predators did not affect the peak numbers of aphids on Hibiscus. However, it did affect the speed of decline of the aphid population: aphid numbers declined more quickly when predators were not removed.

Also, when predation is assessed based on field observations, as in Costamagna and Landis (2007), one can easily calculate from their results that the effect of predators on the aphid population was minute.

All the above lead to the conclusion that predators have little effect on aphid population dynamics in the field (contrary to what occurs in confined situations, like glasshouses), exactly as predicted by the theory. Therefore, no matter whether abundant or not, insect predators have little effect on prey population dynamics, when
GTR is large ("GTR hypothesis", Kindlmann and Dixon 1999a). The simple dynamic model published by Kindlmann and Dixon (1993) demonstrates why the verbal argument presented here is correct.

\section{Intraguild predation}

Intraguild predation has become a major research topic in biological control and conservation ecology. It occurs when two species of predators compete for the same prey and one of them also feeds upon its competitor (Polis et al. 1989). It is assumed to occur widely in many, but not all, guilds of biological-control agents (Rosenheim et al. 1995; Holt and Polis 1997). As a consequence, intraguild predation combines two important structuring forces in ecological communities, competition and predation (Polis and Holt 1992; Polis and Winemiller 1996) and may generate a diversity of indirect effects among co-occurring species (Miller and Brodeur 2002). However, models of intraguild predation are usually based on Lotka-Volterra equations, which are inadequate for modelling population dynamics of aphidophagous insects and their prey (Kindlmann and Dixon 1993, 1999a, b, 2001). In addition, empirical data indicate that the incidence of intraguild predation is most likely much lower than usually assumed (Kindlmann and Houdková 2006).

\section{A metapopulation model}

Based on the above biological assumptions, a model of aphid - natural enemy population dynamics was constructed. For the "tree-type" situation (which includes also large stands of small vascular plants and large solitary vascular plants that can support the complete development of predatory larvae), Kindlmann and Dixon (1993) and Kindlmann et al. (2002) show that the within-season dynamics of this predator-prey system can be described by the following set of differential equations (details described in Kindlmann and Dixon 2003):

$$
\begin{aligned}
& g h / d \mathrm{t}=a x, h(0) 0(1 a) \\
& d x / d t=(\mathrm{r}-h) x-v p x y /(b+p x+y), x(0)=x_{0}(1 b) \\
& d y / d t=-v y^{2} /(b+p x+y) \times y(0)=x_{0}(1 c)
\end{aligned}
$$

Where:

$h(t)$ - cumulative density of the prey at time $t$,

$x(t)$ - density of prey at time $t$,

$a$ - scaling constant relating prey cumulative density to its own dynamics,

$r$ - maximum potential growth rate of the prey,

$y(t)$ - density of predator at time $\mathrm{t}$,

$v$ - predator voracity,

$b$ - parameter of the functional response of the predator, $p$ - predator's preference for prey,

$T$ - time when predator matures; coincides with the duration of a patch of prey, yielding initial values $x(T)$ and $y(T)$ for the next season. 
Equation (1a) describes changes in cumulative density of prey, (1b) describes changes in prey density and (1c) describes the decrease in predator density due to cannibalism. The fractions in eqs. (1b) and (1c) represent Holling's functional response type II for predator eating prey (1b), and predators eating each other (1c). A typical trend in numbers in a patch predicted by model (1) is shown in Fig. 1. There is no predator reproduction in the patch; therefore, predator numbers monotonously decline. As a consequence, if prey abundance $(x)$ increases at the beginning (i.e., if $y(0)$ is sufficiently small, so that $(\lim / t \rightarrow 0+) \times d x / d t>0$ then, as time proceeds, prey population dynamics is less and less influenced by the declining numbers of the predator. Because of the way the diet of the predator is defined (the fractions in (1b) and (1c)), the decline in predator numbers is more pronounced when there are few prey individuals relative to predator individuals. That occurs, when the ratio $x /(x+y)$ is small at the beginning and when prey numbers have passed their peak and become small again due to the negative effect of cumulative density (Kindlmann and Dixon 2003).

The predicted trends in the abundance of predators and prey (Fig. 1) closely match those observed in nature for aphids (Kindlmann and Dixon 1996; Dixon and Kindlmann 1998; Kindlmann et al. 2002) and ladybird beetles (Osawa 1993; Hironori and Katsuhiro 1997; Yasuda and Ohnuma 1999; Kindlmann et al. 2000).

This model was then run for many seasons by Kindlmann and Dixon (2003) and Houdková and Kindlmann (2006), for a set of "patches" and the numbers of both prey and predator at the end of the season were lumped. This simulates both aphids and their natural enemies moving to overwintering sites. Then these individuals were subsequently distributed at random to patches, first aphids and then predators. For the predators, the above-mentioned biological restrictions were considered: they only lay eggs in patches of aphids not yet inhabited by predatory larvae. Then the within-season dynamics was repeated. In this way, an iterative simulation of between-season dynamics was achieved. It is rather difficult to describe the whole set of results, therefore we refer the reader to the original papers in which there is a full description (Kindlmann and Dixon 2003; Houdková and Kindlmann 2006).

This leaves unanswered the question of whether the dynamics on small solitary vascular plants can affect the overall dynamics of the system. Our results indicate that they may not. As predators were observed only rarely on small solitary vascular plants and never repeatedly on the same plant on subsequent visits, these plants may just serve as stepping-stones for adult predators during their search for suitable aphid colonies. Therefore, metapopulation modelling of aphid - natural enemy systems may be justifiably restricted to those vascular plants occurring individually or in stands, which consist of a large area of leaves and stems on which aphids can feed and are also easily accessible to all stages of ladybirds. This, however, needs to be verified.

\section{The importance of vascular plant size in aphid - natural enemy systems}

A $20 \mathrm{~m}$ sycamore tree has 116,000 leaves and can be infested with $2.25 \times 10^{5}$ aphids at any one time during the vegetative season (Dixon 1971), whereas the total area of leaves and stems of small vascular plants is relatively minute compared to that of trees. Many small vascular plants, even the minute Drosophila of the plant world, Arabidopsis thaliana, however, are hosts of generally small specific or host alternating aphids, but the colonies, not surprisingly because space is limiting, tend to be very small and as a consequence rarely used by ladybirds for breeding. Adult aphid predators and sometimes even larvae freely move between aphid colonies/patches on both large vascular plants like trees and on stands of small vascular plants (nettles and cereals) and solitary large herbaceous plants (Anthriscus, Rumex, Verbascum etc.), and on these their immature stages complete their development. Thus, from the perspective of many aphidophagous predators, the aphid metapopulations they exploit consist of many
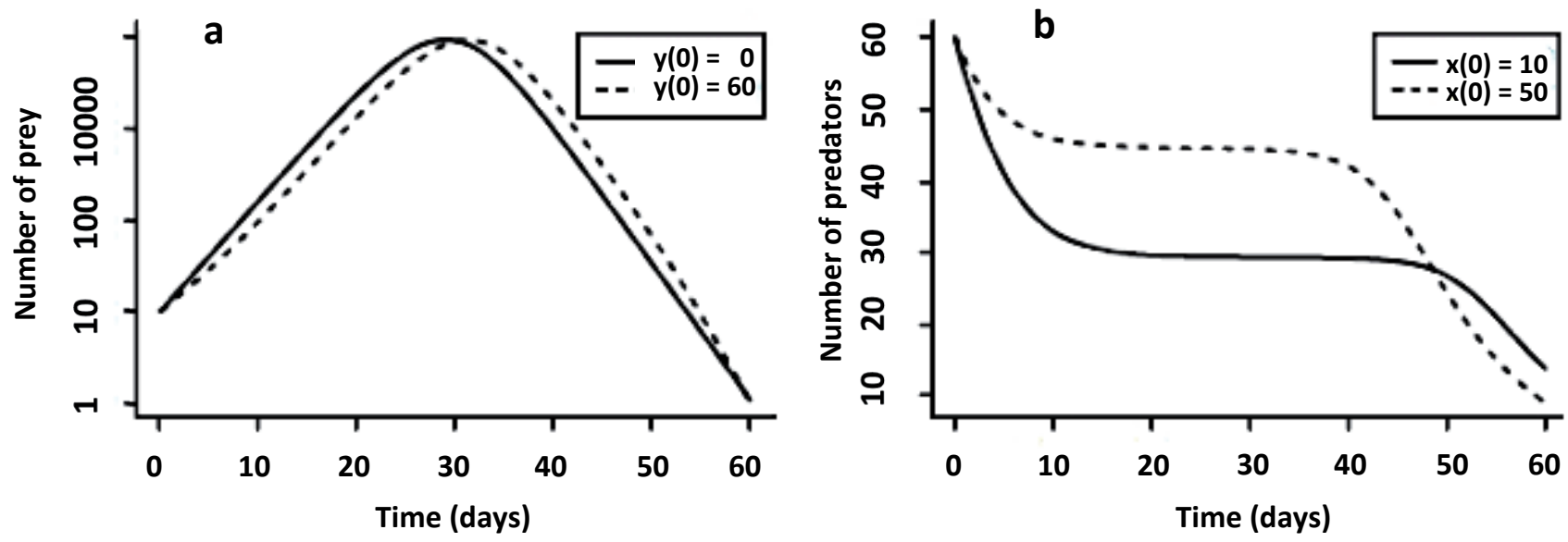

Fig. 1 Trends over time of prey (left) and predator (right) abundances predicted by the within-season model when $a=0.000005, r=0.3, v=$ $0.1, b=0, e=1$, for $y(0)=0$ and $y(0)=60$ (left) and for $x(0)=10$ and $x(0)=50$ (right) - see insets for line codes. 
Table 1 Empirical data, collected in Greece and Czech Republic during 2017-2019: differences between aphid and predator dynamics on large vascular plants (trees) and small solitary vascular plants.

\begin{tabular}{|l|c|c|c|c|}
\hline & $\begin{array}{c}\text { Large vascular plants (trees, stands } \\
\text { of small vascular plants) }\end{array}$ & \multicolumn{3}{|c|}{ Small solitary vascular plants } \\
\hline & Greece 2017 & Greece 2017 & Greece 2018 & Czech Republic 2019 \\
\hline Number of colonies & 9 & 34 & 28 & 64 \\
\hline Number of visits per colony & 24 & 24 & 22 & 32 \\
\hline $\begin{array}{l}\text { Number of colonies with } \\
\text { a"dent" }\end{array}$ & 3 & 21 & 24 & 91 \\
\hline $\begin{array}{l}\text { Number of adult ladybirds } \\
\text { recorded }\end{array}$ & 143 & 2.6 & 3.9 & 9.5 \\
\hline $\begin{array}{l}\text { Percentage of visits, when } \\
\text { adult ladybirds were recorded }\end{array}$ & 66.2 & 39 & 5 & 86 \\
\hline $\begin{array}{l}\text { Number of ladybird larvae } \\
\text { recorded }\end{array}$ & 187 & 4.8 & 0.8 & 9.0 \\
\hline $\begin{array}{l}\text { Percentage of visits, when } \\
\text { ladybird larvae were recorded }\end{array}$ & 86.6 & 0 & & 1 \\
\hline $\begin{array}{l}\text { Number of ladybird pupae } \\
\text { recorded }\end{array}$ & 37 & 0.0 & & \\
\hline $\begin{array}{l}\text { Percentage of visits, when } \\
\text { ladybird pupae were recorded }\end{array}$ & 17.1 & & & \\
\hline
\end{tabular}

populations, each of which consists of many colonies/ patches of aphids. Migration of ladybirds between populations of aphids is mainly by adults that mature in the patches, many of which then leave the aphid population they matured in and reproduce in other suitable aphid populations.

Empirical data, collected in Greece and Czech Republic during 2017-2019, summarized in Table 1 (see Kindlmann et al. (2020) for details of sampling methods), illustrate the differences between the aphid and predator dynamics on large vascular plants and on small solitary vascular plants, which make up a large proportion of the vegetation in grassland landscapes.

It is evident that population dynamics differ greatly between them. On small solitary vascular plants infested with aphids, predators were rarely observed (only about 1-9\% of visits) and their larvae almost never recorded more than once on the same plant (Table 1). This is because it is likely that the larvae only survived for a short period of time and the effect of predatory larvae and adults on the aphid numbers in this colony is just incidental (the "dents" described below). Consequently, far fewer ladybird pupae were recorded on small solitary vascular plants than on large vascular plants. That means that small solitary vascular plants are unlikely to be suitable habitats for the larvae of ladybirds to complete their development, but serve as stepping-stones for adult predators to rest, occasionally lay a few eggs and most likely refuel during their search for patches of aphids suitable for reproduction.

On large vascular plants (trees) and stands of small vascular plants, predators were recorded much more frequently (more than $60 \%$ of visits, Table 1 ), which indicates that predators and aphids were present there con- tinuously long enough for the dynamics described in model (1).

Three types of dynamics were recorded on small solitary vascular plants (Fig. 1). Most commonly, the aphid dynamics followed model (1) described above for when predators are absent (Fig. 1a). Sometimes there was a "dent" in the trend in the aphid population dynamics (Fig. 1b): a sudden decline in the numbers of aphids, followed by quick return to the standard trajectory in population dynamics (Fig. 1b). This could indicate the presence of a (probably adult) predator, which resulted in a significant reduction in the number of aphids, but was not recorded by the observer - most likely because the plant was used just for a short, probably refuelling stop: as a stepping-stone. The reason for the decline might have been different, however: for example, heavy rain, strong wind, or disturbance by large animals. Each of these disturbances might have caused a decline in aphid numbers on the plant, which was not possible to distinguish from the effect of predators. However, aphid numbers always returned to the standard trajectory very quickly. The rare third type of behaviour, illustrated in Fig. 1c, is typical of very small aphid colonies (see the numbers on the $y$-axis), where probably stochastic effects were more important.

In summary, two different habitats need to be considered, when modelling aphid - natural enemy systems: large vascular plants and stands of small vascular plants, and small solitary vascular plants. In the former, model (1) can be used, while the dynamics in the latter can be ignored, as they do not contribute to predator numbers. The approach used by Kindlmann and Dixon (2003) and Houdková and Kindlmann (2006) currently appears to be suitable for the analysis of predator metapopulation dynamics. 


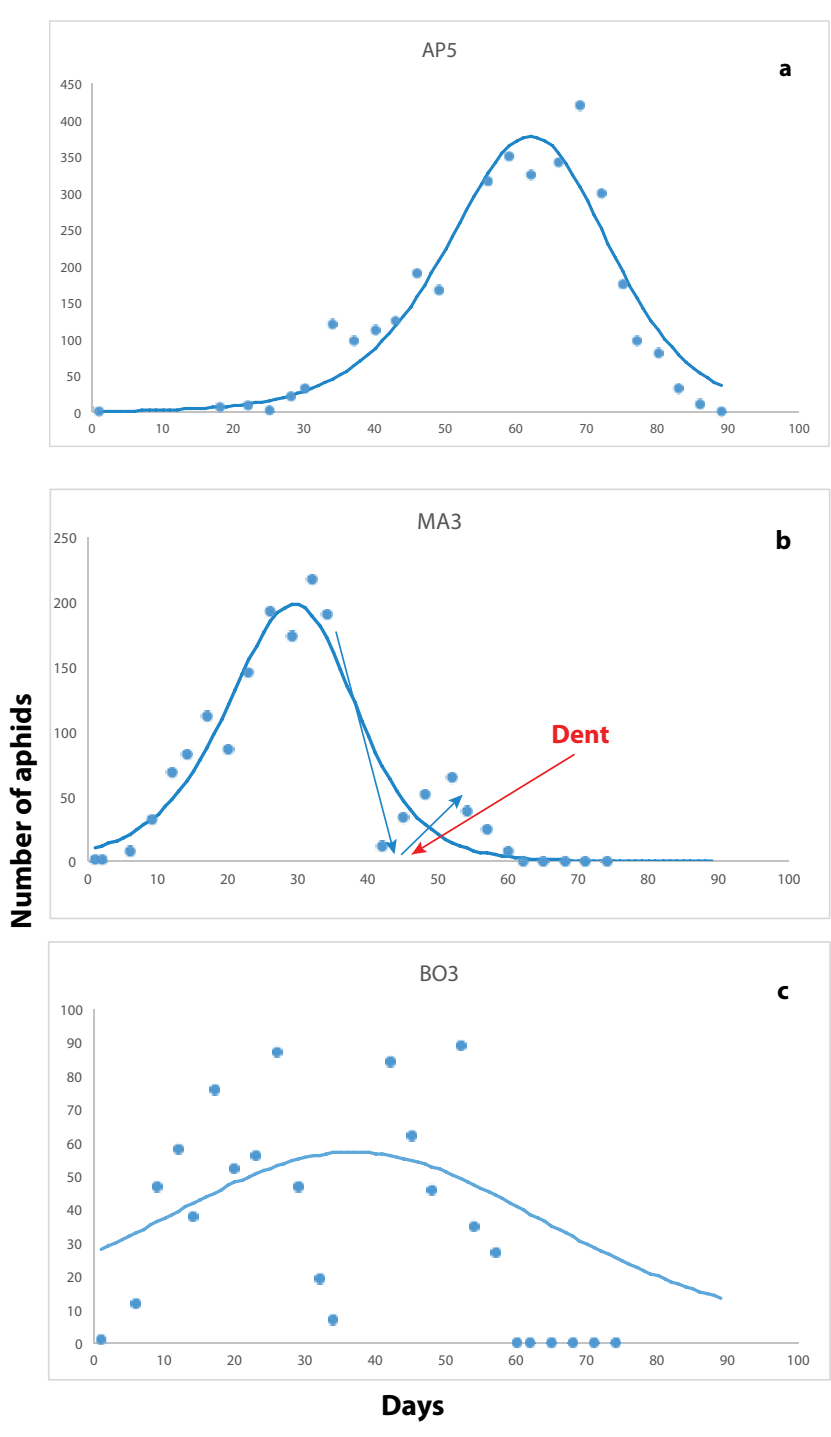

Fig. 2 Three trends in aphid population dynamics were recorded on herbaceous plants growing individually: (a) aphid dynamics followed model (1) described above for when predators are absent; (b) the dynamics described as in (a) with a "dent" near the peak in the upward trend, followed by quick return to the standard population trajectory. The dent is most possibly due to the presence of a predator that reduced aphid numbers significantly; (c) chaotic dynamics, typical of very small aphid colonies, in which stochastic effects were probably the most important.

\section{Other Metapopulation Models for Predatory Insects}

A metapopulation model for modelling predator-prey interactions was used by Nachman (2001) for a system consisting of the two-spotted spider mite (Tetranychus urticae) infesting cucumbers and the phytoseiid predatory mite Phytoseiulus persimilis in greenhouses. However, this system is characterized by a special type of dynamics, "hide-and-seek", characterized by a high rate of turnover of local populations of prey and predators, because once the predators have found a patch of prey they quickly overexploit it, whereupon the starving predators either move to other plants or die (Nachman 2001). Continued persistence of prey and predators thus hinges on a longterm balance between local extinctions and founding of new subpopulations (Nachman 2001). This is not the case for aphid - natural enemy systems, where no overexploitation occurs, except of small colonies on herbaceous plants early in the existence of an aphid colony. Therefore, for the latter system, a modelling approach other than that used by Nachman (2001) must be used. We are not aware of any other metapopulation model that would incorporate dynamics of both insect prey and predator.

\section{Conclusions for the Ladybird-Aphid System}

Using new data, we more closely specify the existing metapopulation model of aphid-ladybird interactions. We have shown that population dynamics of aphid - natural enemy systems can be best modelled by model (1) run for many patches (large vascular plants and stands of small vascular plants). Then the final "autumn" numbers of both aphids and predators should be transferred to spring next year as in Kindlmann and Dixon (2003) and Houdková and Kindlmann (2006).

The biological traits (avoidance of colonies already occupied by predators, laying low numbers of eggs etc.) described here, together with the model predictions may have important consequences for biological control in the field as ladybirds and other insect predators are most unlikely to reduce abundance aphids.

This attempt to describe the aphid- natural enemy dynamics simply in terms of the structure of the plants on which aphids live, hopefully, will stimulate others to test this concept by collecting more data and concentrate on defining plants, not in terms of taxonomy, but in terms of features that are important in determining the fitness of the natural enemies of aphids.

\section{General Conclusions}

The crucial assumptions of our aphid-ladybird metapopulation model that determine its behaviour are:

(1)Prey live in discrete patches (in the case of aphids these are called colonies) regulated by strong intraspecific competition, which - when density is high - results in emigration from the patches; the amount of emigrating individuals is proportional to prey cumulative density.

(2) Adult predators freely move between patches of prey, but immature predators are confined to one patch, because they cannot fly.

(3) There is a strong cannibalism among the predators, if more of them live in the same patch

(4) The ratio of the generation time of the predator to that of its prey (GTR) is large.

These assumptions lead to predictions of the metapopulation dynamics of the system, which coincide well with 
reality. One very important prediction is that percentage mortality of immature predators is very high and therefore there is strong selection for maximising the survival of the offspring, which is much stronger than selection for an increase in voracity. These assumptions and predictions differ from those of classical Lotka-Volterra models, which explains, why these were not successful in modelling insect predator-prey dynamics. Thus voracity, which is the main determinant of population dynamics in Lotka-Volterra models, loses its role and is replaced by optimization of the choice of oviposition sites in systems with large GTRs.

As assumptions (1)-(5) seem to be quite commonly satisfied in many insect predator-prey systems, it seems that the conclusions presented here are quite general in insect predator-prey dynamics. Maybe only the inertia of many people prevents this model from replacing the classical Lotka-Volterra ones.

Finally, the GTR hypothesis can also account for one of the best examples of classical biological control involving a ladybird: that of Rodolia cardinalis controlling a scale insect infesting citrus trees in California (Dixon 2000). In this case the predator has a shorter developmental time than its prey, and as a consequence, as in the Nachman (2001) model, it overexploits its prey, which is then followed by hide-and-seek dynamics.

\section{Acknowledgements}

This work was supported by grant no. 17-06763S of the Grant Agency of the Czech Republic.

\section{REFERENCES}

Agarwala BK, Dixon AFG (1993) Kin recognition: egg and larval cannibalism in Adalia bipunctata (Coleoptera: Coccinellidae). Eur J Entomol 90: 45-50.

Ameixa O, Kindlmann P (2011) Some exclusion cages do not exclude predators. Eur J Environ Sci 1: 67-69.

Basky Z (2003) Predators and parasitoids on different cereal aphid species under caged and co caged conditions in Hungary. In: Soares AO, Ventura MA, Garcia V, Hemptine, JL (eds) Proceedings of the $8^{\text {th }}$ International Symposium on Ecology of Aphidophaga: Biology, Ecology and Behaviour of Aphidophagous Insects, Supplement 5. Arquipélago, Life and Marine Sciences, Ponta Delgada, Azores, Portugal, pp 95-102.

Carpenter B (2018) Predator-prey population dynamics: the Lotka-Volterra model in Stan. https://mc-stan.org/users/documentation/case-studies/lotka-volterra-predator-prey.html. Accessed October 14, 2020.

Cardinale BJ, Harvey CT, Gross K, Ives AR (2003) Biodiversity and biocontrol: emergent impacts of a multi-enemy assemblage on pest sup-pression and crop yield in an agroecosystems. Ecol Lett 6: 857-865. doi: 10.1046/j.1461-0248.2003.00508.x.

Chambers RJ, Sunderland KD, Wyatt IJ, Vickerman GP (1983) The effects of predator exclusion and caging on cereal aphids in winter wheat. J Appl Ecol 20: 209-224. doi: 10.2307/2403387.

Costamagna AC, Landis DA (2006) Predators exert top-down control of soybean aphid across a gradient of agricultural management systems. Ecol Appl 16: 1619-1628.
Costamagna AC, Landis DA (2007) Quantifying predation on soybean aphid through direct field observations. Biol Control 42: $16-24$.

Desneux N, Joo HJ (2006) Suppression of population growth of the soybean aphid, Aphis glycines Matsumura, by predators: the identification of a key predator and the effects of prey dispersion, predator abundance, and temperature. Environ Entomol 35: $1342-1349$.

Dixon AFG (1971) The role of aphids in wood formation. 1. The effect of the sycamore aphid, Drepanosiphum platanoides (Schrk.) (Aphididae), on the growth of sycamore, Acer pseudoplatanus (L.). J Appl Ecol 8: 165-179.

Dixon AFG (2000) Insect Predator-Prey Dynamics: Ladybird Beetles and Biological Control. Cambridge University Press, Cambridge, UK.

Dixon AFG, Hemptinne JL, Kindlmann P (1995) The ladybird fantasy- prospects and limits to their use in the biocontrol of aphids. Zuechtungsforschung- Berichte aus der Bundesanstalt fuer Zuechtungsforschung an Kulturpflanzen 1: 395-397.

Dixon AFG, Hemptinne JL, Kindlmann P (1997) Effectiveness of ladybirds as biological control agents: Patterns and processes. Entomophaga 42: 71-83.

Dixon AFG, Kindlmann P (1998) Generation time ratio and the effectiveness of ladybirds as classical biological control agents, In Pest Management - Future Challenges. In: Zalucki MP, Drew RAI, White GC (eds) Proceedings of 6th Australasian Applied Entomology and Research Conference, Vol.1. The University of Queensland Press, Brisbane, Australia, pp 314-320.

Dixon AFG, Kindlmann P (2012) Cannibalism, optimal egg size and vulnerable developmental stages in insect predators. Eur J Environ Sci 2: 84-88.

Dixon AFG, Sato S, Kindlmann P (2015) Evolution of slow and fast development in predatory ladybirds. J Appl Entomol 140: 103-114. doi: 10.1111/jen.12221.

Dong Q, Polis GA (1992) The Dynamics of Cannibalistic Populations: A Foraging Perspective. In: Elgar MA, Crespi BJ (eds) Cannibalism Ecology and Evolution in Diverse Taxa. Oxford University Press, Oxford, pp 13-37.

Dostálková I, Kindlmann P, Dixon AFG (2002) Are classical predator-prey models relevant to the real world? J Theor Biol 218: 323-330.

Doumbia M, Hemptinne JL, Dixon AFG (1998) Assessment of patch quality by ladybirds: role of larval tracks. Oecologia 113: 197-202.

Elliott NC, Kieckhefer RW (2000) Response by coccinellids to spatial variation in cereal aphid diversity. Pop Ecol 42: 81-90. doi: $10.1007 / \mathrm{s} 101440050012$.

Fox LR (1975) Cannibalism in natural populations. Annu Rev Ecol Syst 6: 87-106.

Frazer BD, Gilbert N (1976) Coccinellids and aphids: a quantitative study of the impact of adult ladybirds (Coleoptera: Coccinellidae) preying on field populations of pea aphids (Homoptera: Aphididae). J Ent Soc BC 73: 33-56.

Frazer BD, Gilbert N, Ives PM, Raworth DA (1981) Predator reproduction and the overall predator-prey relationship. Can Entomol 113: 1015-1024.

Hand LF, Keaster AJ (1967) The environment of an insect field cage. J Econ Entomol 60: 910-915. doi: 10.1093/jee/60.4.910.

Hassell MP (1978) The Dynamics of Arthropod Predator-prey Systems. Princeton University Press, Princeton, New Jersey, USA.

Hironori Y, Katsuhiro S (1997) Cannibalism and interspecific predation in two predatory ladybirds in relation to prey abundance in the field. Entomophaga 42: 153-163. 
Holt RD, Polis GA (1997) A theoretical framework for intraguild predation. Am Nat 149: 745-764.

Hoppenstead F (2006) Predator-prey model. Scholarpedia 1: 1563.

Houdková K, Kindlmann P (2006) Scaling up population dynamic processes in a ladybird-aphid system. Popul Ecol 48: 323-332. doi: 10.1007/s10144-006-0007-3.

Kareiva P (1990) Population dynamics in spatial complex environments: theory and data. Philos T Roy Soc B 330: 175-190.

Kindlmann P, Arditi R, Dixon AFG (2002) A simple aphid population model. In: Simon JC, Dedryver CA, Rispe C, Hulle M (eds) Proceedings of the Sixth International Symposium on Aphids "Aphids in a New Millenium". INRA, Rennes, France, pp 325-330.

Kindlmann P, Dixon AFG (1993) Optimal foraging in ladybird beetles (Coleoptera: Coccinellidae) and its consequences for their use in biological control. Eur J Entomol 90: 443-450.

Kindlmann P, Dixon AFG (1996) Population dynamics of a tree-dwelling aphid: Individuals to populations. Ecol Model 89: 23-30.

Kindlmann P, Dixon AFG (1999a) Generation time ratios- determinants of prey abundance in insect predator-prey interactions. Biol Control 16: 133-138.

Kindlmann P, Dixon AFG (1999b) Strategy of aphidophagous predators: lessons for modelling insect predator-prey dynamics. J Appl Entomol 123: 397-399.

Kindlmann P, Dixon AFG (2001) When and why top-down regulation fails in arthropod predator-prey systems. Basic Appl Ecol 2: 333-340.

Kindlmann P, Dixon AFG (2003) Insect predator-prey dynamics and the biological control of aphids by ladybirds. In: Forest Health Technology Enterprise Team (eds) First International Symposium on Biological Control of Arthropods. USDA, Morgantown, West Virginia, USA, pp 118-124.

Kindlmann P, Houdková K (2006) Intraguild predation: fiction or reality? Popul Ecol 48: 317-322. doi: 10.1007/s10144-0060006-4.

Kindlmann P, Štípková Z, Dixon AFG (2020) Aphid colony duration does not limit the abundance of Harmonia axyridis in the Mediterranean area. Sci Rep, in review.

Kindlmann P, Yasuda H, Kajita Y, Sato S, Dixon AFG (2015) Predator efficiency reconsidered for a ladybird-aphid system. Front Ecol Evol 3: 27. doi: 10.3389/fevo.2015.00027.

Kindlmann P, Yasuda H, Sato S, Shinya K (2000) Key life stages of two predatory ladybird species (Coleoptera: Coccinellidae). Eur J Entomol 97: 495-499.

Kirby RD, Ehler IF (1977) Survival of Hippodamia convergens in grain sorghum. Environ Entomol 6: 777-780.

Lotka AJ (1920) Analytical Note on Certain Rhythmic Relations in Organic Systems. Proceedings of the National Academy of Science of the United States of America 6: 410-415. doi:10.1073/ pnas.6.7.410.

Lotka AJ (1925). Elements of Physical Biology. Science Progress in the Twentieth Century (1919-1933) 21: 341-343.

Matsura T (1976) Ecological studies of a coccinellid, Aiolocaria hexaspilota Hope I. Interaction between field populations of $A$. hexaspilota and its prey, the walnut leaf beetle (Gastrolina depresa Baly). Jpn J Ecol 26: 147-156.
Michels GJ, Elliot NC, Romero RA, Owings DA, Bible JB (2001) Impact of indigenous coccinellids on Russian what aphids and green-bugs (Homoptera: Aphididae) infesting winter wheat in the Texas Panhandle. Southwestern Entomol 26: 97-114.

Miller CB, Brodeur J (2002) Intraguild predation in biological control and conservation biology. Biol Control 25: 216-223.

Mills NJ (1982) Voracity, cannibalism and coccinellid predation. Ann Appl Biol 101: 144-148.

Mills NJ (2018) An alternative perspective for the theory of biological control. Insects 9: 131. doi: 10.3390/insects9040131.

Nachman G (2001) Predator-prey interactions in a nonequilibrium context: the metapopulation approach to modeling "hideand-seek" dynamics in a spatially explicit tri-trophic system. Oikos 94: 72-88. doi: 10.1034/j.1600-0706.2001.11314.x.

Nielsen C, Hajek AE (2005) Control of invasive soybean aphid, Aphis glycines (Hemiptera: Aphididae), populations by existing natural enemies in New York State, with emphasis on entomopathogenic fungi. Environ Entomol 34: 1036-1047.

Osawa N (1993) Population-field studies of the aphidophagous ladybird beetle Harmonia axyridis (Coleoptera, Coccinellidae) life-tables and key factor-analysis. Res Popul Ecol 35: 335-348.

Polis GA, Holt RD (1992) Intraguild predation: the dynamics of complex trophic interactions. TREE 7: 151-154.

Polis GA, Myers CA, Holt RD (1989) The ecology and evolution of intraguild predation: potential competitors that eat each other. Annu Rev Ecol Syst 20: 297-330.

Polis GA, Winemiller KO (1996) Food webs: integration of patterns and dynamics. Chapman and Hall, New York, USA.

Rosenheim JA, Kaya HK, Ehler LE, Marois JJ, Jaffee BA (1995) Intraguild predation among biological-control agents: theory and evidence. Biol Control 5: 303-335.

Rutledge CE, O’Neil RJ (2005) Orius insidiosus (Say) as a predator of the soybean aphid, Aphis glycines Matsumura. Biol Control 33: 56-64.

Rutledge CE, O’Neil RJ, Fox T, Landis D (2004) Soybean aphid predators and their use in integrated pest management. Ann Entomol Soc Am 97: 240-248.

Schmidt MH, Lauer A, Purtauf T, Thies C, Schaefer M, Tscharntke T (2003) Relative importance of predators and parasitoids for cereal aphid control. Proc Roy Soc B 270: 1905-1909. doi: 10.1098/rspb.2003.2469

Varley GC, Gradwell GR, Hassell MP (1974) Insect Population Ecology: An Analytical Approach. University of California Press, Berkeley and Los Angeles, USA.

Volterra V (1926) Variazioni e fluttuazioni del numero d'individui in specie animali conviventi. Mem Acad Lincei Roma 2: 31-113.

Volterra V (1931) Variations and fluctuations of the number of individuals in animal species living together. In: Chapman RN (ed) Animal Ecology with especial Reference to Insects. McGraw-Hill, New York and London, pp 409-448.

Wright EJ, Laing JE (1982) Stage-specific mortality of Coleomegilla maculata lengi Timberlake on corn in Southern Ontario. Environ Entomol 11: 32-37.

Yasuda H, Ohnuma N (1999) Effect of cannibalism and predation on the larval performance of two ladybird beetles. Entomol Exp Appl 93: 63-67. 